\title{
MYXOMYCETES DO PARQUE ZOOBOTÂNICO DE TERESINA, PIAUÍ, BRASIL
}

\author{
Márcia Percília Moura Parente Ponte ${ }^{1}$ \\ Laise de Holanda Cavalcanti ${ }^{2}$ \\ Mitra Mobin ${ }^{3}$
}

Recebido em 09/01/2001. Aceito em 09/09/2001

\begin{abstract}
RESUMO - (Myxomycetes do Parque Zoobotânico de Teresina, Piauí, Brasil). Visando ampliar o conhecimento sobre a mixobiota do Piauí, foram realizadas coletas no Parque Zoobotânico de Teresina $\left(05^{\circ} 05^{\prime} 12^{\prime \prime} \mathrm{S}, 42^{\circ} 48^{\prime} 48^{\prime}\right.$ " WG). A vegetação do Parque caracteriza-se como um cerradão com representantes da mata de cocais, que oferecem substratos potencialmente favoráveis ao desenvolvimento de Myxomycetes. Esporocarpos foram coletados no período chuvoso e início da estiagem (março a junho de 1999), identificados e depositados no herbário UFP (Universidade Federal de Pernambuco). Foram obtidas 101 amostras, correspondentes a 19 espécies, distribuídas nas famílias Ceratiomyxaceae (Ceratiomyxa fruticulosa (Mull.) Macbr., Clastodermataceae (Clastoderma debaryanum Blytt), Cribrariaceae (Cribraria microcarpa (Schrad.) Pers., C. violacea Rex, Dictydium canceilatum* (Batsch.) Macbr.), Enteridiaceae (Lycogala exiguum* Morgan.), Physaraceae (Craterium aureum* (Schum.) Rost., Physarum bogoriense* Racib., P. melleum (Berk. \& Br.) Massee, P. nucleatum Rex, P. pusilium* (Berk. \& Curt.) G. Lister), Trichiaceae (Arcyria denudata (L.) Wett., A. cinerea (Bull.) Pers., Hemitrichia calyculata (Speg.) Farr, H. serpula (Scop.) Rost., Metatrichia vesparium (Batsch) Nann.-Brem., Perichaena depressa Lib.) e Stemonitaceae (Comatricha typhoides (Bull.) Rost., Stemonitis smithii Macbr.). Exceto H. calyculata e H. serpula, todos os táxons são referidos pela primeira vez para o município de Teresina; as espécies assinaladas com um asterisco constituem novos registros para o Piauí.
\end{abstract}

Palavras-chave - Myxomycetes, Parques estaduais, cerrado, Piauí

\begin{abstract}
Myxomycetes of the Parque Zoobotânico - Teresina, Piauí, Brazil). Aiming to increase the knowledge about the myxobiota of Piauí State, Brazil, collections were done in the undertaken Zoobotanical Park of Teresina $\left(05^{\circ} 05^{\prime} 12^{\prime}\right.$ ' S, $\left.42^{\circ} 48^{\prime} 48^{\prime \prime} \mathrm{WG}\right)$. The vegetation of the Park is a savanna ("cerradão") with "cocais" forest representative, offering substrates potentially favorable to the development of Myxomycetes. Sporocarps were collected in the rainy season (March to June 1999), identified and deposited at the UFP herbarium (Federal University of Pernambuco). One hundred and one samples were collected, corresponding to 19 species, distributed in the families: Ceratiomyxaceae (Ceratiomyxa fruticulosa (Mull.) Macbr., Clastodermataceae (Clastoderma
\end{abstract}

1 Departamento de Biologia, CCBS, Universidade Estadual do Piaú, Av. João Cabral s/n, CEP 64002-150 Teresina, PI, Brasil (marciapercilia@zipmail.com.br)

2 Departamento de Botânica, CCB, Universidade Federal de Pernambuco, Av. Prof. Moraes Rego s/n, CEP 50670-901 Recife, PE, Brasil (lhcandrade@hotmail.com)

3 Centro Federal de Educação Tecnológica do Piauí, Praça da Liberdade 1597, Centro, CEP 64000-040 Teresina, PI, Brasil. CNPq-DCR (mitra@cefetpi.br) 
debaryanum Blytt), Cribrariaceae (Cribraria microcarpa (Schrad.) Pers., C. violacea Rex, Dictydium cancellatum* (Batsch.) Macbr.), Emeridiaceae (Lycogala exiguum* Morgan), Physaraceae (Craterium aureum*(Schum.) Rost., Physarum bogoriense* Racib., P. melleum (Berk. \& Br.) Massee, P. nucleatum Rex, P. pusilium*(Berk. \& Curt.) G. Lister), Trichiaceae (Arcyria denudata (L.) Wett., A. cinerea (Bull.) Pers., Hemitrichia calyculata (Speg.) Farr, H. serpula (Scop.) Rost., Metatrichia vesparium (Batsch) Nann.-Brem., Perichaena depressa Lib.) and Stemonitaceae (Comatricha typhoides (Bull.) Rost., Stemonitis smithii Macbr.). With the exception of H. calyculata and H. serpula, all taxa are referred for the first time for the Municipality of Teresina, and the species with an asterisk constitute new record for the State of Piauí.

Key words - Myxomycetes, State Parks, savanna, Piauí

\section{Introdução}

O Parque Zoobotânico de Teresina está situado no setor nordeste do perímetro urbano da cidade, entre o rio Poty, principal afluente do rio Parnaíba e a PI-112, que liga a capital ao interior do Estado. O Parque é uma área de preservação ambiental administrada pelo poder público através da Secretaria Estadual do Meio Ambiente e Recursos Hídricos - SEMAR e é utilizado também como zoológico, abrigando espécies animais americanas e africanas. Compreende área de 160 ha que se caracteriza como mata mista dicótilo-palmácea. Entre os representantes da mata de cocais, destacam-se Altalea speciosa Mart. ex Spreng. (babaçu), Astrocaryum vulgare Mart. (tucum) e Acrocomia intumescens Drude (macaúba); dentre os representantes de cerrado tipo cerradão, predominam Dimorphandra gardneriana Tul. (fava-d'anta), Hymenaea courbaril L. (jatobá), Cenostigma gardnerianum Tul. (canela de velho), Lecythis pisonis Camb. (sapucaia), Tabebuia serratifolia (Vahl) Nich. (pau-d'arco) e Astronium fraxinifolium Schott. (gonçaloalves). Em algumas áreas do Parque percebemse indícios do avanço da antropização, pelo aparecimento de espécies típicas desse tipo de ação, como a Mimosa caesalpiniifolia Benth.

Estudos realizados em Parques Nacionais e Unidades de Conservação no Nordeste do Brasil têm relatado a ocorrência de numerosas espécies de Myxomycetes (Góes Neto 1996; Rizzuto 1997; Cavalcanti et al. 1993). Em
Pernambuco, por exemplo, Pôrto (1982) realizou estudo na Mata de Dois Irmãos (Reserva de Floresta Estacional Perenifólia Costeira), onde relacionou 104 espécies de Myxomycetes, sendo as mais freqüentes Arcyria cinerea (Bull.) Pers., A. denudata (L.) Wett., Ceratiomyxa fruticulosa (Mull.) Macbr., Hemitrichia calyculata (Speg.) Farr, H. serpula (Scop.) Rost., Lycogala epidendrum (L.) Fries, Metatrichia vesparium (Batsch) Nann.-Brem., Perichaena depressa Lib., Physarum nucleatum Rex, Stemonitis axifera (Bull.) Macbr., S. fusca Roth e Tubifera microsperma (Berk. \& Curt.) Martin. Para o Piauí, Mobin (1997) iniciou os estudos de Myxomycetes e fungos micófilos em áreas de mata ciliar e cerrado no Parque Nacional de Sete Cidades, município de Piripiri, onde evidenciou que a mixobiota é bastante diversificada e que a vegetação de cerrado é propícia para o desenvolvimemo desses organismos. Mobin \& Cavalcanti (1999a, 1999b), também no Parque Nacional de Sete Cidades, levantaram as espécies de Myxomycetes das ordens Stemonitales e Physarales, assim como estudaram a mixobiota encontrada em Mauritia fiexuosa L. f e Copernicia prunifera (Miller) H. E. Moore (Mobin \& Cavalcanti, 1998/1999; 2000); estes estudos registraram, até o momemo, a ocorrência de 45 espécies, representando as três subclasses e todas as ordens de Myxomycetes.

Com intuito de ampliar o conhecimento da mixobiota no Estado do Piauí e tornar melhor conhecida a distribuição geográfica dos 
Myxomycetes no Brasil, táxons pertencentes às subclasses Ceratiomyxomycetidae, Myxogastromycetidae e Stemonitomycetidae encontrados no Parque Zoobotânico de Teresina são descritos e comentados.

\section{Material e métodos}

Entre março e junho/1999, foram realizadas coletas no Parque Zoobotânico de Teresina (05 05' 12' S, 42 ${ }^{\circ} 48$ ' 48', WG), onde pesquisou-se a presença de esporocarpos de Myxomycetes em troncos (vivos ou mortos), folhas, inflorescências e frutos caídos ao solo, em vegetação do tipo cerradão.

Os esporocarpos encontrados foram coletados com seus respectivos substratos, herborizados e identificados (Cavalcanti 1974; Farra 1976; Mobin 1997); exsicatas foram depositadas no Herbário UFP (Departamento de Botânica, Universidade Federal de Pernambuco).

Adotou-se o sistema de classificação de Martin et al. (1983) para gêneros e categorias supragenéricas. Hagelstein (1944), Lister (1925), Martin \& Alexopoulos (1969), Farr (1976) e Lado \& Pando (1997) foram consultados para identificação das amostras. As descrições e ilustrações das espécies foram baseadas no material estudado, adotando-se a terminologia indicada por Teixeira (1971), Farr (1976) e Lado \& Pando (1997).

A distribuição geográfica no Brasil baseou-se nos trabalhos de Cavalcanti \& Fortes (1994; 1995); Góes Neto (1996); Hochgesand \& Gottsberger (1996); Putzke (1996); Mobin (1997); Cavalcanti \& Putzke (1998); Cavalcanti et al. (1999); Mobin \& Cavalcanti (1998/1999; 1999a; 1999b; 2000). A distribuição mundial baseou-se em Martin \& Alexopoulos (1969), Farra (1976) e Lado \& Pando (1997).

\section{Resultados e discussão}

No presente estudo foram registradas 19 espécies, distribuídas em 13 gêneros e sete famílias, representando todas as subclasses e ordens de Myxomycetes. Destas, apenas Hemitrichia calyculata (Speg.) Farr e $H$. serpula (Scop.) Rost. já haviam sido referidas para a microrregião onde se situa o município de Teresina. Dictydium canceilatum (Batsch.) Macbr., Lycogala exiguum Morgan, Craterium aureum (Schum.) Rost., Physarum bogoriense Racib. e P. pusillum (Berk. \& Curt.) G. Lister são novas referências para o Estado do Piauí.

\section{Ceratiomyxaceae}

Ceratiomyxa fruticulosa (Müll.) Macbr., N. Am. Slime-Moulds 18.1899.

Fig. 1-3.

Frutificação branco leitosa, esporóforo ramificado, 3-4mm alt., elevando-se em colunas. Esporo elipsóide a globoso, hialino, liso, 6,12-7,65 $\times$ 9,18-10,71 $\mu \mathrm{m}$ diâm., preso ao esporóforo de comprimento uniforme.

Distribuição: cosmopolita. No Brasil, ocorre nas regiões Norte (AM, AP, PA, RR), Nordeste (AL, BA, CE, PB, PI), Sudeste (SP) e Sul (RS, $\mathrm{SC})$.

Comentários: os exemplares coletados, apesar de escassos, são típicas frutificações de Ceratiomyxa fruticulosa var. flexuosa Lister, táxon não reconhecido por Martin \& Alexopoulos (1969), que o consideram apenas como uma das expressões da espécie em resposta a determinadas condições ambientais. Esta espécie é muito comum no Nordeste e em todo Brasil e foi recentemente referida para o município de Piripiri, PI por Mobin (1997) e Mobin \& Cavalcanti (2000).

Material examinado: BRASIL. Piauí: Teresina, Parque Zoobotânico, cerradão, área sombreada, 27/III/1999, Parente-Ponte 17 (UFP 27354); idem, 10/IV/1999, Parente-Ponte 41 (UFP 27355).

\section{Clastodermataceae}

Clastoderma debaryanum Blytt, Bot. Zeit. 38:343.1880.

Fig. 4-6.

Esporângio pedicelado, globoso, agrupado, 
castanho avermelhado, 2,0-3,0 $\mathrm{mm}$ alt. total; perídio simples, persistente na base da esporoteca como um colar; hipotalo castanho-avermelhado, circular, membranoso; pedicelo cilíndrico afinando abruptamente para o ápice no ponto onde apresenta uma dilatação, castanho-avermelhado, $2,76 \mu \mathrm{m}$ compr. $\times$ $122,40 \mu \mathrm{m}$ larg. na base $\times 45,90 \mu \mathrm{m}$ larg. no ápice; columela dividindo-se em 2-3 ramos principais; capilício filamentoso, castanho-claro, ramificado, com tendência à dicotomia, liso; esporo globoso, castanho pálido, quase liso, 7,2-10,3 $\mu \mathrm{m}$ diâm.

Distribuição: América Central, América do Norte, América do Sul, Ásia, Austrália, Europa. No Brasil, ocorre nas regiões Nordeste (PE, PI), Sudeste (SP) e Sul (SC).

Comentários: obteve-se apenas uma amostra desta espécie, apresentando as características típicas do pedicelo e capilício, as quais permitiram enquadrá-la bem na chave e descrição de Martin \& Alexopoulos (1969). Mobin (1997) referiu esta espécie pela primeira
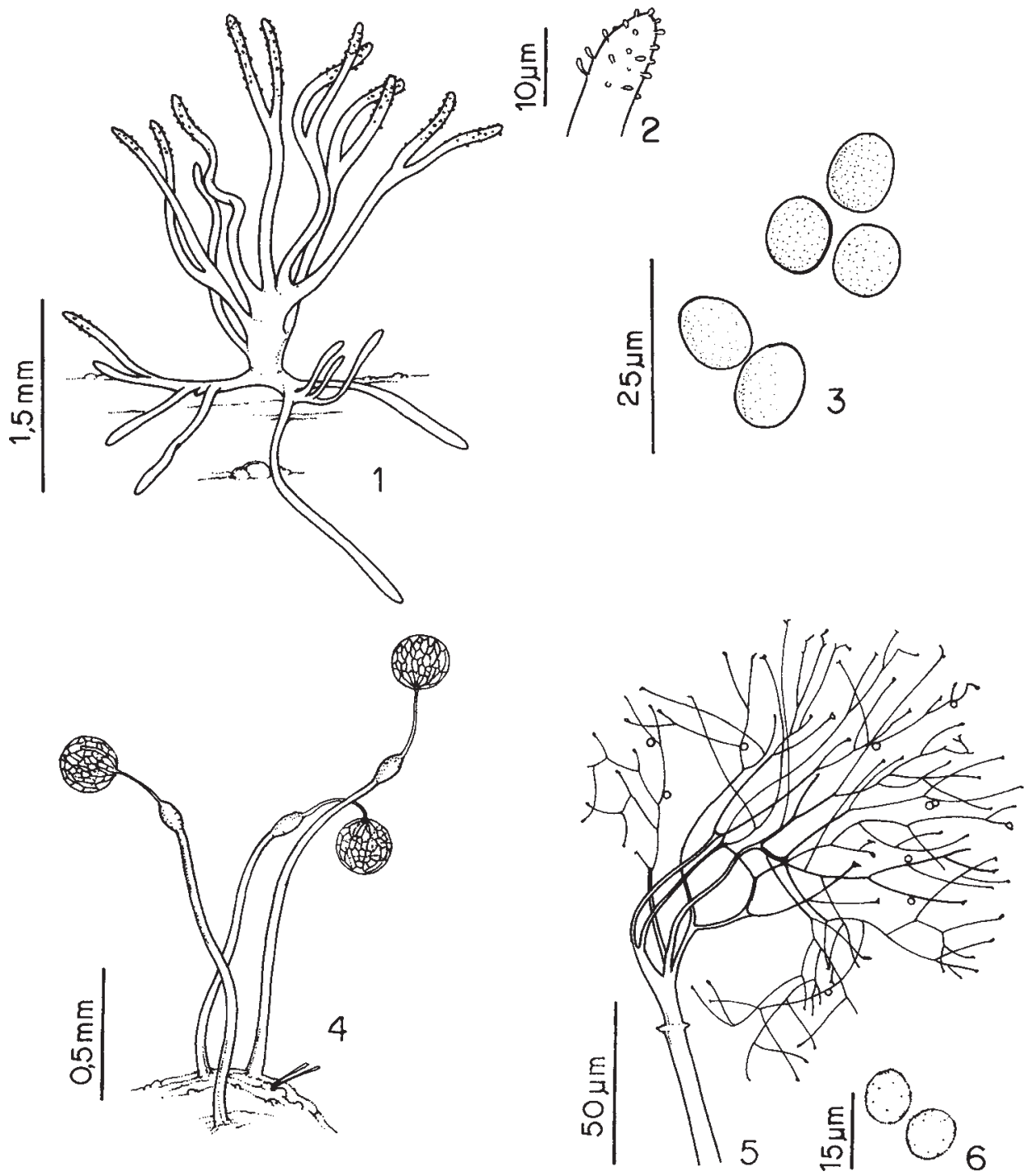

Figuras 1-3. Ceratiomyxafruticulosa (Müll.) Macbr.: 1. frutificação; 2. extremidade de um ramo; 3. esporos. 4-6. Clastoderma debaryanum Blytt.; 4. esporângios; 5. esporoteca evidenciando a pequena columela e capilício; 6. esporos. 
vez para o Piauí.

Material examinado: BRASIL. Piauí:

Teresina, Parque Zoobotânico, cerradão, área sombreada, 18/IV/1999, Parente-Ponte 51 (UFP 27357); câmara úmida, 11/VI/1999, Parente-Ponte 106 (UFP 27356).

Cribrariaceae

Cribraria microcarpa (Schrad.) Pers., Syn. Fung. 190. 1801, emend. Nann.-Brem., K. Ned. Akad. Wet. Proc. C. 69:340. 1966.

Fig. 7-8.

Esporângio pedicelado, globoso, isolado, castanho-avermelhado, 1,9-2,1 mm alt. total; hipotalo castanho-avermelhado, circular, membranoso; pedicelo sulcado longitudinalmente, cilíndrico, afilando para o ápice, $1500 \mu \mathrm{m}$ compr. $\times 100 \mu \mathrm{m}$ larg. na base $\times 175 \mu \mathrm{m}$ larg. no ápice; grânulos dictidinos castanho-escuro, 1,0-1,5 $\mu \mathrm{m}$ diâm.; rede peridial com nódulos castanhos, em

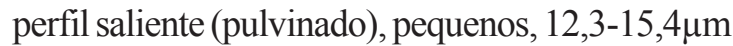
diâm., poucos filamemos conectantes, raramente apresentando pontas livres e semelhantes a espinhos; calículo presente em alguns esporocarpos; esporo globoso, amarelo pálido a hialino, quase liso, 5,1-6,1 $\mu \mathrm{m}$ diâm.

Distribuição: amplamente distribuída na África, América do Norte, América do Sul, Ásia, Europa, Japão, Nova Zelândia. No Brasil, ocorre nas regiões Norte (RR), Nordeste (PB, PE, PI), Sudeste (SP), Sul (PR).

Comentários: espécie referida pela primeira vez para o Piauí por Mobin (1997). Os exemplares analisados, quanto ao tamanho dos esporos e pela cor mais clara dos grânulos dictidinos, se aproximam de Cribraria pachydictyon Nann.Brem., porém esta espécie possui nódulos pulvinados levemente côncavos e esporos maiores.

Material examinado: BRASIL. Piauí: Teresina, Parque Zoobotânico, cerradão, área sombreada 10/IV/1999, Parente-Ponte 37 (UFP 27364); idem, 18/IV/1999, Parente-Ponte 66 (UFP 27363); ); idem, 1/V/1999, ParentePonte 79 (UFP 27362); idem, câmara úmida,
30/VI/1999, Parente-Ponte 107 (UFP 27361).

Cribraria violacea Rex, Proc. Acad. Phila. 43:393.1891.

Fig. 9-11.

Esporângio pedicelado, globoso a subgloboso, isolado, violeta escuro, $1,35 \mathrm{~mm}$ alt. total; hipotalo castanho-violáceo escuro, circular, membranoso; pedicelo sulcado longitudinalmente, cilíndrico afilando para o ápice, $1300 \mu \mathrm{m}$ compr. $\times 15,3 \mu \mathrm{m}$ larg. na base $\times 61,2 \mu \mathrm{m}$ larg. no ápice; grânulos dictidinos violeta, $1,0-1,5 \mu \mathrm{m}$ diâm., rede peridial com grandes nódulos violeta claro, achatados, raras pontas livres; calículo presente, ocupando metade ou pouco mais da esporoteca; esporo globoso, violeta pálido a quase hialino, livre, levememe verrucoso, 6,12-7,65 $\mu \mathrm{m}$ diâm.
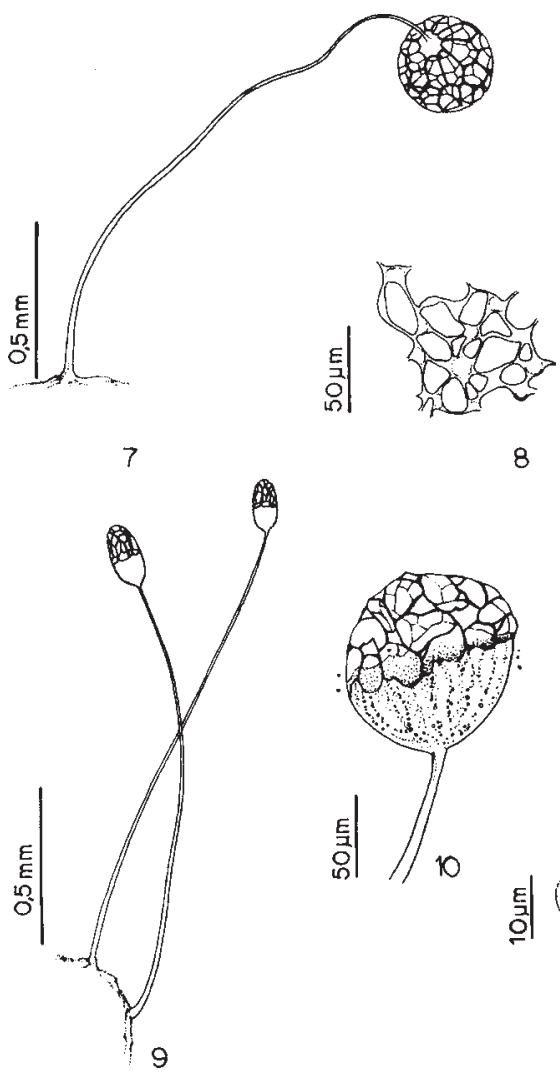

8

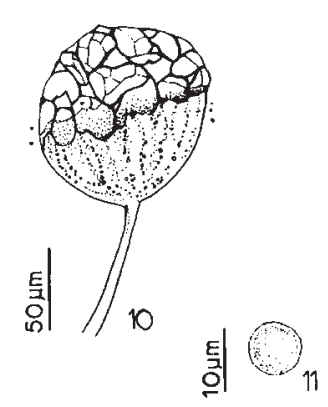

Figuras 7-8. Cribraria microcarpa (Schrad.) Pers. 7. esporângio; 8. rede peridial. 9-11. Cribraria violacea Rex. 9. esporângios; 10. esporoteca evidenciando o profundo calículo e grânulos dictidinos; 11. esporo. 
Distribuição: cosmopolita. No Brasil, ocorre nas regiões Nordeste (CE, PE, PI) e Sudeste (SP).

Comemários: espécie referida para o Parque Nacional de Sete Cidades, registrada sobre Mauritia flexuosa L.f. (Mobin 1997; Mobin \& Cavalcami 1998/1999). O único exemplar coletado na presente pesquisa encontra-se muito deteriorado por fungos, porém conserva as características típicas da espécie.

Material examinado: BRASIL. Piauí: Teresina, Parque Estadual Zoobotânico, cerradão, área sombreada 10/IV/1999, ParentePonte 34 (UFP 27338).

Dictydium cancellatum (Batsch) Macbr., N. Am. Slime-Moulds 172. 1899.

Fig. 12-13.

Esporângio pedicelado, isolado, castanho-avermelhado, esporoteca globosa, umbilicada, 3,5mm alt. total; perídio em rede, castanho, com pontas livres e linhas transversais conectando as costelas; grânulos dictidinos ao longo de pomos mais resistemes do perídio; pedicelo cilíndrico, castanho-avermelhado; esporo globoso, hialino, quase liso, 5,1-7,21 $\mu \mathrm{m}$ diâm.

Distribuição: cosmopolita. No Brasil, ocorre nas regiões Norte (AM, RR), Nordeste (BA, CE, PB, PE), Sudeste (SP, RJ) e Sul (PR).

Comemários: espécie comum no Brasil, sobre diversos substratos. Apresenta grânulos dictidinos característicos do gênero, dispostos ao longo de pontos mais resistentes do perídio (costelas), mas ausentes nos filamemos transversais. D. mirabile (Rost.) Meylan foi referido recemememe para o Brasil por Mobin \& Cavalcami (1998/1999), com base em material coletado no Parque Nacional de Sete Cidades, no Piauí; esta espécie é muito próxima de $D$. cancellatum porém quase não apresenta os numerosos e delicados filamentos transversais que tipicamente conectam as costelas, além dos esporângios possuírem um calículo profundo, características não encontradas no material coletado em Teresina.

Material examinado: BRASIL. Piauí: Teresina, Parque Zoobotânico, cerradão, área sombreada, 16/V/1999, Parente-Ponte 98 (UFP 27335).

\section{Enteridiaceae}

Lycogala exiguum Morgan, Jour. Cinc. Soc. Nat. Hist. 15: 134. 1893.

Fig. 14-16.

Etálio séssil, semi-globoso, isolado, pardoacinzentado, 2,0mm alt. $\times 2,5 \mathrm{~mm}$ diâm.; hipotalo inconspícuo, bege; pseudocapilício ramificado, enrugado, margens não crenadas, 4,5-6,1 $\mu \mathrm{m}$ diâm.; córtex persistente, deiscência apical; esporo globoso, bege a quase hialino por luz transmitida, livre, reticulado, 5,1-6,8(7,6) $\mu \mathrm{m}$ diâm.

Distribuição: cosmopolita. No Brasil, ocorre nas regiões Nordeste (PE), Sudeste (SP) e Sul (SC).

Comentários: o gênero Lycogala já foi citado para o Piauí por Mobin (1997), que refere a presença de Lycogala epidendrum (L.) Fries no Parque Nacional de Sete Cidades, em Piripiri. $\mathrm{O}$ único exemplar encontrado no Parque Zoobotânico de Teresina desenvolveu-se em tronco caído, confirmando a preferência das espécies desse gênero por material lignificado e bem decomposto.

Material examinado: BRASIL. Piauí: Teresina, Parque Zoobotânico, cerradão, área sombreada, 16/V/1999, Parente-Ponte 98-b (UFP 27341 ).

Trichiaceae

Arcyria cinerea (Bull.) Pers., Syn. Fung. 184. 1801.

Fig. 17-18.

Esporângio pedicelado, cilíndrico a subcilíndrico, às vezes ovóide, isolado a agrupado, castanho-acinzentado, 2,0-3,2 $\mathrm{mm}$ alt. total; perídio simples, persistente na base formando um pequeno calículo; hipotalo castanhoavermelhado, membranoso e levemente brilhoso; 


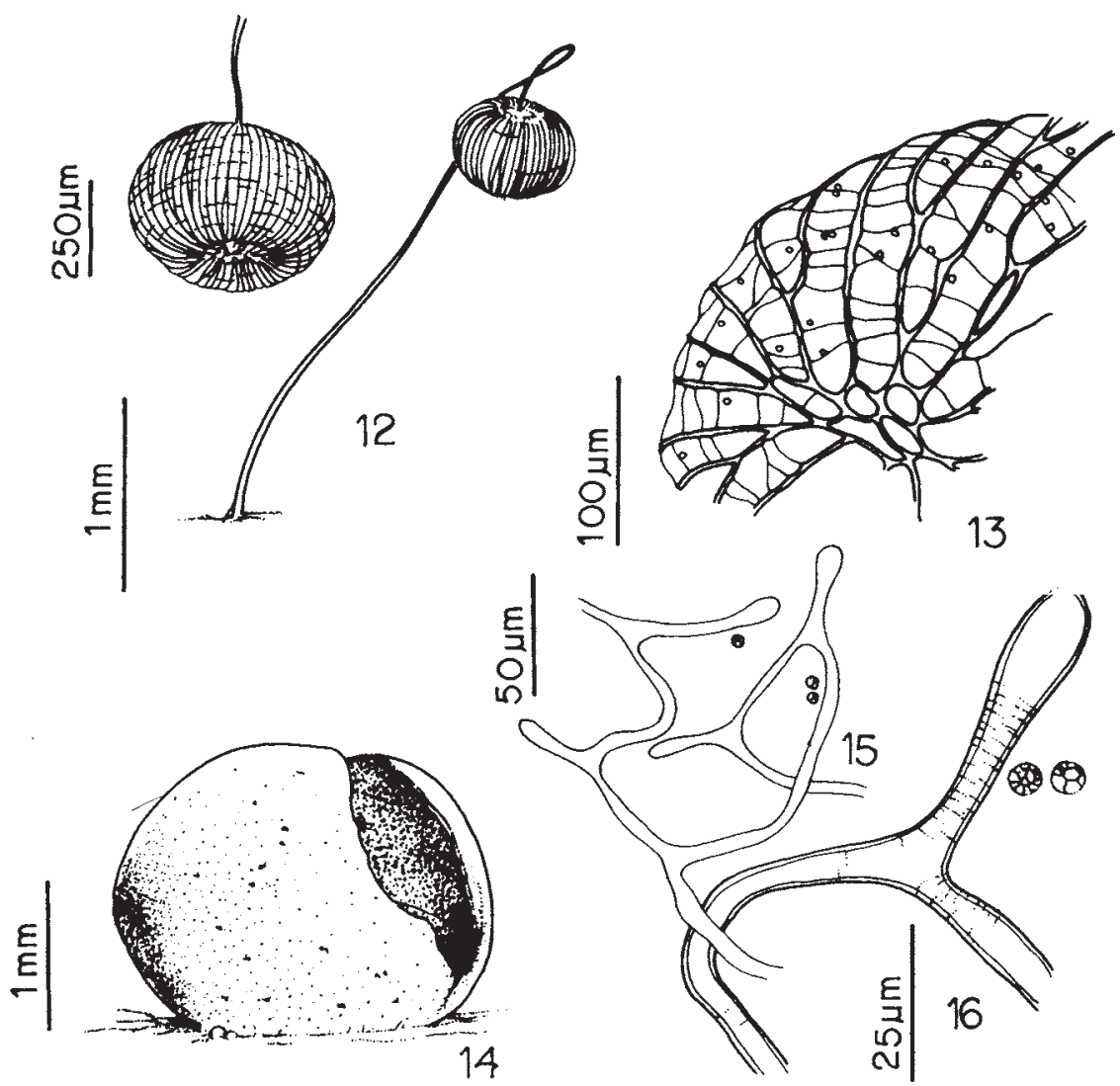

Figuras 12-13. Dictydium cancellatum (Batsch) Macbr. 12. esporângio e esporoteca; 13. detalhe da rede peridial. 14-16. Lycogala exiguum Morgan. 14. etálio; 15. pseudocapilício evidenciando a ramificação; 16. detalhe do pseudocapilício e esporos.

pedicelo cilíndrico com a base um pouco dilatada, castanho-escuro, $(0,67) 0,92-1,52(1,8) \mu \mathrm{m}$ compr. $\times 122,4-153,0 \mu \mathrm{m}$ larg. na base $\times 91,8-168,0 \mu \mathrm{m}$ larg. no ápice; capilício firmemente preso às bordas do calículo, filamentoso, mais dilatado e liso na base, castanho-claro a hialino, ramificado, com tendência à dicotomia, minutamente espinulado no ápice, pontas livres; esporo globoso, castanho-claro, quase hialino, $(4,5) 6,1-7,6(9,1) \mu \mathrm{m}$ diâm.

Distribuição: cosmopolita. No Brasil, ocorre nas regiões Norte (AC, AM, PA, RR), Nordeste (AL, BA, CE, PB, PE, PI, RN), Sudeste ( R J, SP) e Sul (PR, RS, SC).

Comemários: os exemplares analisados apresentam as características típicas da espécie. Farra (1960) e Pôrto et al. (1985) relataram a ocorrência de $A$. cinerea sobre diferentes substratos para o Brasil e a região Nordeste. Mobin \& Cavalcanti (1998/1999) registraram pela primeira vez a presença dessa espécie no Piauí.

Material examinado: BRASIL. Piauí: Teresina, Parque Zoobotânico, cerradão, área sombreada, 27/III/1999, Parente-Ponte 01 (UFP 27393); idem, 27/III/1999, Parente-Ponte 08 (UFP 27385); idem, 27/III/1999, ParentePonte 09 (UFP 27386); idem, 10/IV/1999, Parente-Ponte 32 (UFP 27388); idem, 10/IV/ 1999, Parente-Ponte 42 (UFP 27389); idem, 18/IV/1999, Parente-Ponte 52 (UFP 27394); idem, 18/IV/1999, Parente-Ponte 65 (UFP 27395); idem, 1/V/1999, Parente-Ponte 88 (UFP 27396); idem, 1/V/1999, Parente-Ponte 99 (UFP 27397); área iluminada 27/III/1999, Parente-Ponte 24 (UFP 27387); idem, 
27/III/1999, Parente-Ponte 25 (UFP 27390); idem, 11/IV/1999, Parente-Ponte 49 (UFP 27391); idem, 11/IV/1999, Parente-Ponte 50 (UFP 27392).

Arcyria denudata (L.) Wett., Verh. Zool.-Bot. Ges. Wien 35: Abh. 535. 1886.

Fig. 19-20.

Esporângio pedicelado, cilíndrico, isolado a agrupado, vermelho-ferrugíneo, 2,0-3,0 mm alt. total; perídio simples, persistente na base como um calículo; hipotalo circular a irregular, castanho-avermelhado, membranoso e brilhante; pedicelo cilíndrico, castanho-avermelhado, $1,61 \mathrm{~mm}$ compr. $\times 214,2 \mu \mathrm{m}$ larg. na base $\times$ $183,6 \mu \mathrm{m}$ larg. no ápice; capilício abundante, elástico, filamentoso, com tendência à dicotomia,

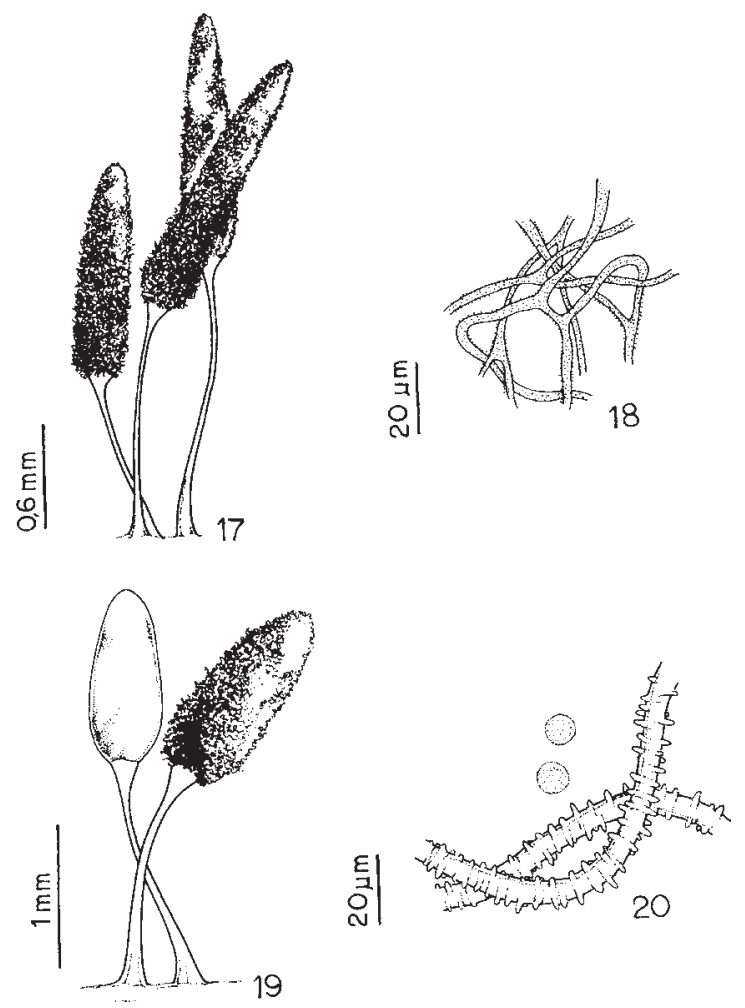

Figuras 17-18. Arcyria cinerea (Bull.) Pers. 17. esporângios; 18. capilício. 19-20. Arcyria denudata (L.) Wett. 19. esporângios; 20. detalhe do capilício evidenciando a omamentação e esporos. pontas livres, ornamentado por dentes pontiagudos e anéis, 6,1-7,6um diâm.; esporo globoso, castanho-claro a hialino, 6,1-7,6 $\mu$ m diâm.

Distribuição: cosmopolita. No Brasil, ocorre nas regiões Norte (AM, RO, RR), Nordeste (BA, CE, PB, PE, PI), Sudeste (RJ, SP) e Sul (PR, RS, SC).

Comentários: os poucos exemplares coletados apresentam características típicas da espécie, de acordo com Martin \& Alexopoulos (1969), facilitando sua identificação. O capilício está firmemente preso às bordas do calículo nos exemplares analisados, o que facilita sua distinção de outras espécies do gênero com a mesma coloração. Mobin \& Cavalcanti (2000) citam pela primeira vez a ocorrência de A. denudata no Piaú.

Material examinado: BRASIL. Piauí: Teresina, Parque Zoobotânico, cerradão, área sombreada, 18/IV/1999, Parente-Ponte 56 (UFP 27358); idem, 1/V/1999, Parente-Ponte 85 (UFP 27359); área iluminada 16/V/1999, Parente-Ponte 102 (UFP 27360).

Hemitrichia calyculata (Speg.) Farr, Mycologia 66: 887. 1974.

Fig. 21-22.

Esporângio pedicelado, subgloboso a piriforme, isolado a agrupado, amarelo-claro, $(1,5) 2,5-3,2(3,5) \mathrm{mm}$ alt. total; perídio simples, persistente como um calículo bem definido, ocasionalmente com bordas revolutas, face interna delicada e papilosa; hipotalo castanho-avermelhado, brilhante, circular, membranoso; pedicelo cilíndrico, sendo a base mais dilata$\mathrm{da}$, castanho-avermelhado $(0,5) 1,0-1,75(2,0) \mu \mathrm{m}$ compr. $\times(100) 200-500(750) \mu \mathrm{m}$ larg. na base $\times$

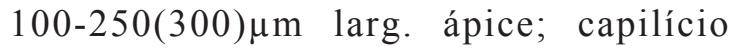
filamentoso, com espirais e estrias transversais, amarelo, ramificado com pontas livres; esporo globoso a oval, amarelo, levememe espinulado, $(5,1) 6,1-8,2(9,27) \mu$ m diâm.

Distribuição: cosmopolita. No Brasil, ocorre nas regiões Norte (AM, RR), Nordeste (BA, CE, PB, PE, PI), Sudeste (SP, RJ) e Sul (PR, RS, SC). 
Comemários: os espécimes analisados são muito típicos, apesar de constatar-se uma pequena variação no tamanho do pedicelo e no calículo. Em várias regiões do Brasil, incluindo o Nordeste, esta espécie é muito freqüente, sendo registrada em diferentes tipos de vegetação por Pôrto et al. (1985), Alves \& Cavalcanti (1996), Mobin (1997), Mobin \& Cavalcanti (1998/1999) e Parente-Ponte et al. (1999).

Material examinado: BRASIL. Piauí: Teresina, Parque Estadual Zoobotânico, cerradão, área sombreada, 27/III/1999, ParentePonte 05 (UFP 27403); idem, 27/III/1999, Parente-Ponte 06 (UFP 27410); idem, 27/III/1999, Parente-Ponte 15 (UFP 27412); idem, 27/III/1999, Parente-Ponte 19 (UFP 27399); idem, 10/IV/1999, Parente-Ponte 33 (UFP 27408); idem, 10/IV/1999, Parente-Ponte 38 (UFP 27413); idem, 10/IV/1999, ParentePonte 39 (UFP 27415); idem, 18/IV/1999, Parente-Ponte 57 (UFP 27411); idem, 18/IV/1999, Parente-Ponte 61 (UFP 27417); idem, 18/IV/1999, Parente-Ponte 77 (UFP 27402); idem, 16/V/1999, Parente-Ponte 90 (UFP 27414); idem, 16/V/1999, Parente-Ponte 93 (UFP 27416); idem, 18/IV/1999, ParentePonte 55 (UFP 27400); idem, 18/IV/1999, Parente-Ponte 59 (UFP 27405); idem, 18/IV/1999, Parente-Ponte 62 (UFP 27409); idem, 18/IV/1999, Parente-Ponte 78 (UFP 27406); idem, 16/V/1999, Parente-Ponte 91 (UFP 27407); idem, 16/V/1999, Parente-Ponte 95 (UFP 27398); área iluminada 16/V/1999, Parente-Ponte 100 (UFP 27404); idem, 16/V/1999, Parente-Ponte 101 (UFP 27401 ).

Hemitrichia serpula (Scop.) Rost. in Lister, Mycet. 179. 1894.

Fig. 23-24.

Plasmodiocarpo extenso, formando retículo ramificado, amarelo intenso; perídio simples e delicado, membranoso, não evanescente, deiscência longitudinal à irregular; capilício muito elástico, expandido, filamemoso, com espirais e estrias transversais, $(11,3) 12,0-18,0(20,6) \mu \mathrm{m}$ diâm. (incluindo espinhos), amarelo-ouro, espinhos abundantes e longos, 3,0-10,3 $\mu \mathrm{m}$ compr.; esporo amarelo-claro, globoso, nitidamente reticulado, 10,7-15,3 $\mu \mathrm{m}$ diâm.

Distribuição: cosmopolita. No Brasil, ocorre nas regiões Norte (AM, RR), Nordeste (BA, CE, PB, PE, PI,), Sudeste (SP, RJ) e Sul (PR, $\mathrm{RS}, \mathrm{SC})$.

Comentários: os espécimes analisados apresentam características tipicas de Hemitrichia serpula. É uma espécie cosmopolita, encontrada em todas as regiões do Brasil, em diferentes substratos. Mobin (1997) cita a ocorrência dessa espécie no Parque Nacional de Sete Cidades e Parente-Ponte et al. (1999) registraram sua presença no Parque Zoobotânico de Teresina. Nas numerosas amostras analisadas, as medidas encontradas para o esporo e o capilício, incluindo os espinhos, não se enquadram na variedade piauiensis, proposta por Cavalcanti \& Mobin (2001) com base em material coletado em Piripiri, PI.

Material examinado: BRASIL. Piauí: Teresina, Parque Zoobotânico, cerradão, área sombreada, 27/III/1999, Parente-Ponte 02 (UFP 27418); idem, 27/III/1999, Parente-Ponte 04 (UFP 27419); idem, 27/III/1999, Parente-Ponte 07 (UFP 27420); idem, 27/III/1999, ParentePonte 11 (UFP 27421); idem, 27/III/1999, Parente-Ponte 16 (UFP 27422); idem, 10/IV/1999, Parente-Ponte 27 (UFP 27424); idem, 10/IV/1999, Parente-Ponte 31 (UFP 27425); idem, 10/IV/1999, Parente-Ponte 35 (UFP 27426); idem, 18/IV/1999, Parente-Ponte 54 (UFP 27429); idem, 18/IV/1999, ParentePonte 64 (UFP 27430); idem, 18/IV/1999, Parente-Ponte 69 (UFP 27431); idem, 18/IV/1999, Parente-Ponte 73 (UFP 27432); idem, 18/IV/1999, Parente-Ponte 74 (UFP 27433); idem, 18/IV/1999, Parente-Ponte 75 (UFP 27434); idem, 1/V/1999, Parente-Ponte 80 (UFP 27435); idem, 1/V/1999, Parente-Ponte 82 (UFP 27436); idem, 1/V/1999, Parente-Ponte 
83 (UFP 27437); idem, 1/V/1999, Parente-Ponte 86(UFP 27438); idem, 1/V/1999, Parente-Ponte 87 (UFP 27439); idem, 16/V/1999, ParentePonte 89 (UFP 27440); idem, 16/V/1999, Parente-Ponte 94 (UFP 27441); idem, 16/V/1999, Parente-Ponte 96 (UFP 27442); área iluminada 27/III/1999, Parente-Ponte 23 (UFP 27423); idem, 10/IV/1999, Parente-Ponte 43 (UFP 27427); idem, 10/IV/1999, ParentePonte 48 (UFP 27428).

Perichaena depressa Lib., PI. Crypt. 378. 1837.

Fig. 25-26.

Esporângio séssil, poligonal, achatado, numeroso, agrupado a raramente isolado, 0,1-3,0mm larg.; perídio duplo, camada externa cartilaginosa, castanho-avermelhada, camada interna membranosa, amarelada, iridescente; capilício filamentoso, abundante, elástico, delicado, levemente verrucoso, amarelo-claro, 1,4-2,1 $\mu \mathrm{m}$ diâm.; esporo globoso, amarelo-pálido, levemente verrucoso, $(7,4) 8,4-9,8(14,0) \mu \mathrm{m}$ diâm.

Distribuição: cosmopolita. No Brasil, ocorre nas regiões Nordeste (BA, CE, PB, PE, PI), Sudeste (RJ, SP) e Sul (SC).

Comentários: a espécie é próxima de Perichaena quadrata Macbr., diferindo pelo menor tamanho dos esporocarpos e pela rugosidade do capilício (Keller \& Eliasson 1992). As características presentes nos exemplares analisados permitiram identificá-los seguramente como P. depressa, com base na chave e descrição de Farr (1976) para a região Neotrópica; percebeu-se uma variação no diâmetro do esporo, que se apresentou maior em algumas amostras. É uma espécie de ampla distribuição mundial, bastante tolerante a grandes variações de umidade.

Material examinado: BRASIL. Piauí: Teresina, Parque Zoobotânico, cerradão, área sombreada, 27/III/1999, Parente-Ponte 03 (UFP 27376); idem, 27/III/1999, Parente-Ponte 12 (UFP 27377); idem, 27/III/1999, Parente-Ponte 14 (UFP 27378), idem, 27/III/1999, Parente-
Ponte 18 (UFP 27373); idem, 27/III/1999, Parente-Ponte 20 (UFP 27374); idem, 27/III/1999, Parente-Ponte 21 (UFP 27382); idem, 10/IV/1999, Parente-Ponte 28 (UFP 27380); idem, 18/IV/1999, Parente-Ponte 60 (UFP 27383); idem, 1/V/1999, Parente-Ponte 81 (UFP 27384); idem, 1/V/1999, Parente-Ponte 84 (UFP 27379); área iluminada 27/III/1999, Parente-Ponte 22 (UFP 27381); idem, 16/V/1999, Parente-Ponte 103 (UFP 27375).

Metatrichia vesparium (Batsch) Nann.Brem., Proc. Neder. Akad. Wet. C. 69: 146.1966.

Fig. 27-28.

Esporângio pedicelado, obovado, agrupado, vermelho-acastanhado, 1,0-2,5mm alt. total; perídio duplo, o interno membranoso e o externo cartilaginoso, persistente, deiscência opercular; hipotalo circular a irregular, castanho-avermelhado, membranoso e brilhante; pedicelo cilíndrico, agrupado em fascículos, castanho-avermelhado, $1125 \mu \mathrm{m}$ compr. $\times 150 \mu \mathrm{m}$ larg. na base $\times 100 \mu \mathrm{m}$ larg. no ápice; capilício avermelhado, abundante, elástico, ramificado, com pontas livres, filamentoso, 12,3-15,45 $\mu \mathrm{m}$ diâm. (incluindo os espinhos), ornamentado com bandas de espirais e estrias longitudinais, espinhos com 5,15-7,21 $\mu \mathrm{m}$ diâm.; esporo globoso, castanho-claro a hialino, levemente verrucoso, 10,3-11,3 $\mu$ m diâm.

Distribuição: amplamente distribuída no Hemisfério Norte e menos encontrada no Hemisfério Sul. No Brasil, ocorre nas regiões Norte (AM), Nordeste (BA, PE, PI), Sudeste (RJ, SP) e Sul (RS, SC).

Comemários: durante o período de estudo, apenas uma amostra desta espécie foi coletada, porém muito típica. Embora não seja freqüente nos locais onde ocorre, apresenta ampla distribuição no país, não sendo referida apenas para a Região Centro-Oeste (Putzke 1996). No Nordeste, foi assinalada desde o início do século para a Bahia (Torrend 1915), como Hemiarcyria rubiformis (Pers.) Rost.; posteriormente, foi 

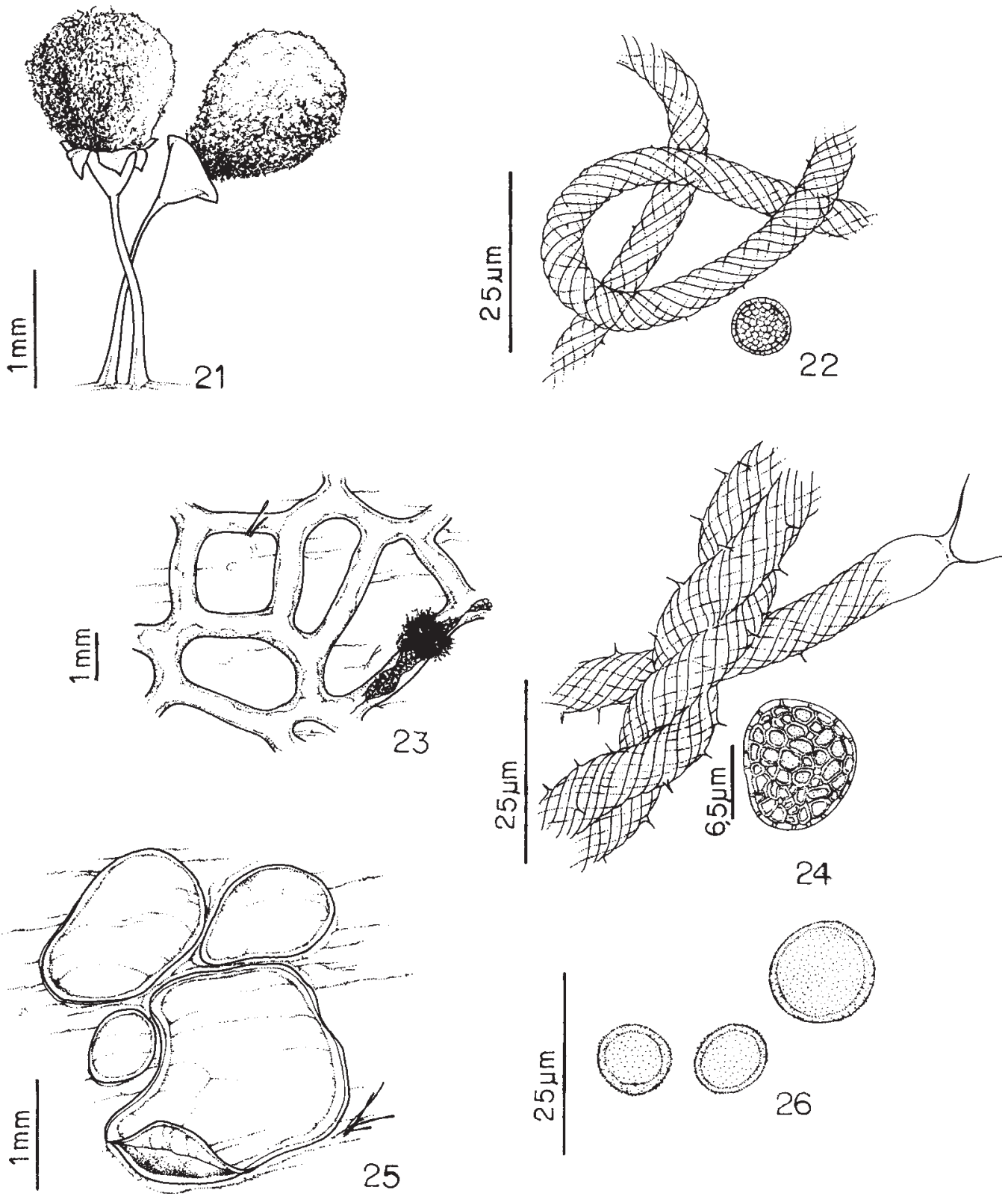

Figuras 21-22. Hemitrichia calyculata (Speg.) Farr. 21. esporângios evidenciando o caliculo com bordas revolutas; 22. detalhe do capilício e esporo. 23-24. Hentitrichia serpula (Scop.) Rost. 23. detalhe do plasmodiocarpo reticulado; 24. detalhe do capilício espinesceme e esporo reticulado. 25-26. Perichaena depressa Lib. 25. esporângios sésseis evidenciando a linha de deiscência do perídio; 26. esporos. 
registrada em Pernambuco (Pôrto 1982) e, mais recentemente, no Piauí (Mobin 1997).

Material examinado: BRASIL. Piauí: Teresina, Parque Zoobotânico, cerradão, área iluminada, 16/VI/1999, Parente-Ponte 104 (UFP 27337).

Physaraceae

Craterium aureum (Schum.) Rost., Mon. 124. 1874.

Fig. 29-31.

Esporângio pedicelado, ciatiforme, isolado a agrupado, amarelo-ferrugíneo, 1,0 mm alt. total; perídio simples, fortemente incrustado com cálcio amarelo; hipotalo castanho-ferrugíneo, circular, membranoso e brilhante; pedicelo cilíndrico, curto, castanho-ferrugíneo, 300-367,2 $\mu \mathrm{m}$ compr. $\times 91,8 \mu \mathrm{m}$ larg. na base $\times 61,2-122,4 \mu \mathrm{m}$ larg. no ápice; capilício filamentoso, ramificado, abundante, nódulos de cálcio angulosos $(10,9) 16,8-48,9 \mu \mathrm{m}$ diâm.; pseudocolumela presente em alguns esporocarpos; esporo globoso, castanho-violáceo, levemente verrucoso, 7,6-9,1 1 m diâm.

Distribuição: cosmopolita. No Brasil, ocorre nas regiões Norte (AM, RR), Nordeste (BA, PB, PE, PI), Sudeste (SP) e Sul (PR, RS, SC).

Comentários: a espécie é facilmente reconhecida pela cor e deiscência do perídio e presença de pseudocolumela. Nos exemplares
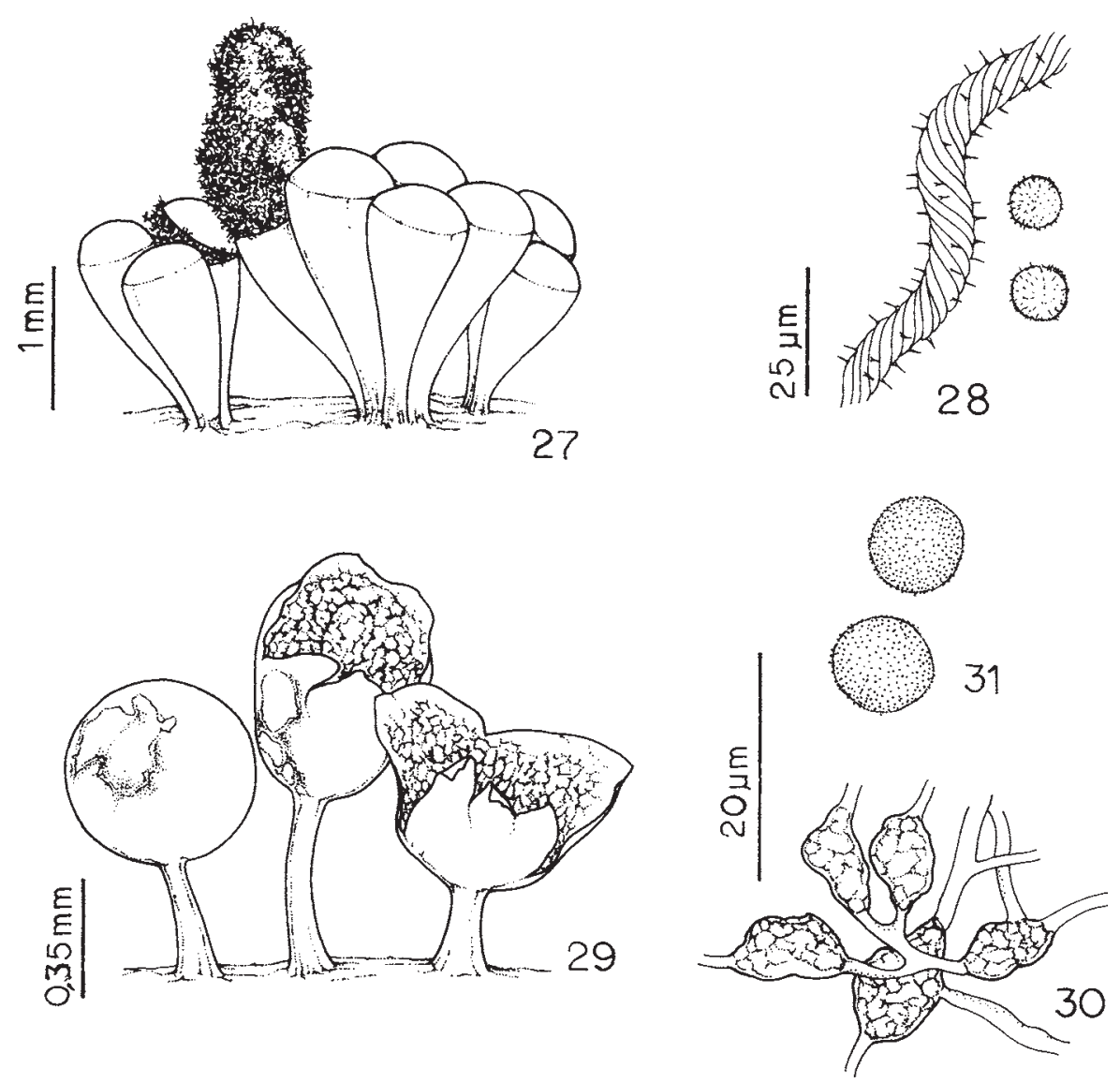

Figuras 27-28. Metatrichia vesparium (Batsch) Nann.-Brem. 27. esporângios evidenciando a deiscência operculada; 28. detalhe do capilício espinescente e esporos. 29-31. Craterium aureum (Schum.) Rost. 29. esporângios, no centro a pseudocolumela; 30 . capilício com nódulos de cálcio; 31 . esporos. 
estudados, os esporos são um pouco menores do que os descritos por Martin \& Alexopoulos (1969).

Material examinado: BRASIL. Piauí: Teresina, Parque Zoobotânico, cerradão, área sombreada, 18/IV/1999, Parente-Ponte 68 (UFP 27343); idem, 16/V/1999, Parente-Ponte 97 (UFP 27344).

Physarum bogoriense Racib., Hedwigia 37:52.18F. 1898.

Fig. 32-34.

Plasmodiocarpo alongado, castanho-pálido, agrupado; perídio duplo, camada interna membranosa, delicada e iridescente, camada externa cartilaginosa, bege, deiscência longitudinal por lobos reflexos; nódulos do capilício brancos, quase hialinos, 15,3 × 26,0 $\mu \mathrm{m}$ diâm., conectados por finíssimos filamentos; esporo globoso, ocasionalmente agrupado, castanho-violáceo, quase liso, 7,6-9,1 $\mu$ m diâm.

Distribuição: cosmopolita. No Brasil, ocorre nas regiões Nordeste (BA, PB, PE), Sudeste (SP) e Sul (RS, SC).

Comentários: o único exemplar coletado apresentava numerosos esporocarpos, em ótimo estado de conservação. As características analisadas são típicas da espécie, como descrita por Martin \& Alexopoulos (1969).

Material examinado: BRASIL. Piauí: Teresina, Parque Zoobotânico, cerradão, área sombreada, 10/IV/1999, Parente-Ponte 29 (UFP 27339).

Physarum melleum (Berk. \& Br.) Massee, Mon. 278. 1892.

Fig. 35-36.

Esporângio pedicelado, globoso, isolado a agrupado, amarelo-claro a cor de mel, 1,0-1,5mm alt. total; perídio simples, parcialmente evanescente, irregular; hipotalo branco, recoberto por cálcio, circular, membranoso; pedicelo cilíndrico, curto, afinando para o ápice, calcário, branco, 382,5-535,5 $\mu \mathrm{m}$ compr. $\times$ 91,8-168,3 $\mu \mathrm{m}$ larg. na base $\times 76,5-91,8 \mu \mathrm{m}$ larg. no ápice; columela muito curta, cônica, contendo cálcio; esporo globoso, castanho-violáceo, tendência a agrupar, levemente verrucoso, 7,6-9,1 1 m diâm.

Distribuição: cosmopolita. No Brasil, ocorre nas regiões Norte (AM), Nordeste (BA, PE, PI), Sudeste (SP) e Sul (PR, SC).

Comentários: o material estudado apresenta perídio com a coloração típica que deu origem ao epíteto específico; em alguns exemplares é bem visível a presenqa de uma pequena columela cônica, características que se enquadram nas descrições encontradas em Martin \& Alexopoulos (1969) e Farr (1976). Esta espécie foi referida para o Piauí por Mobin \& Cavalcanti (1999a).

Material examinado: BRASIL. Piauí: Teresina, Parque Zoobotânico, cerradão, área sombreada 16/V/1999, Parente-Ponte 92 (UFP 27353); área iluminada, 11/IV/1999, ParentePonte 47 (UFP 27345).

Physarum nucleatum Rex, Proc. Acad. Phila. 43: 389. 1891.

Fig. 37-38.

Esporângio pedicelado, globoso, isolado, castanho pardacento, $1,5 \mathrm{~mm}$ alt. total; perídio simples, persistente; hipotalo circular, castanho, membranoso; pedicelo cilíndrico, castanho claro, $1250 \mu \mathrm{m}$ compr. $\times 170 \mu \mathrm{m}$ larg. na base $\times 30 \mu \mathrm{m}$ larg. no ápice; capilício escasso, hialino, dicotomicamente ramificado, nódulos de cálcio 10,3 × 7,2 m diâm.; esporo globoso, castanho-violáceo, agrupado, quase liso a levemente verrucoso, 7,2-8,2 $\mu \mathrm{m}$ diâm.

Distribuição: África, América do Norte, América Central e América do Sul, Ásia, Europa. No Brasil, ocorre nas regiões Norte (AM, RR), Nordeste (CE, PE, PI), Sudeste (SP) e Sul (PR).

Comentários: o único exemplar analisado, obtido em câmara-úmida, apresenta características muito típicas da espécie, já referida para o Piauí por Mobin \& Cavalcanti (1999a).

Material examinado: BRASIL. Piauí: Teresina, Parque Zoobotânico de Teresina, 

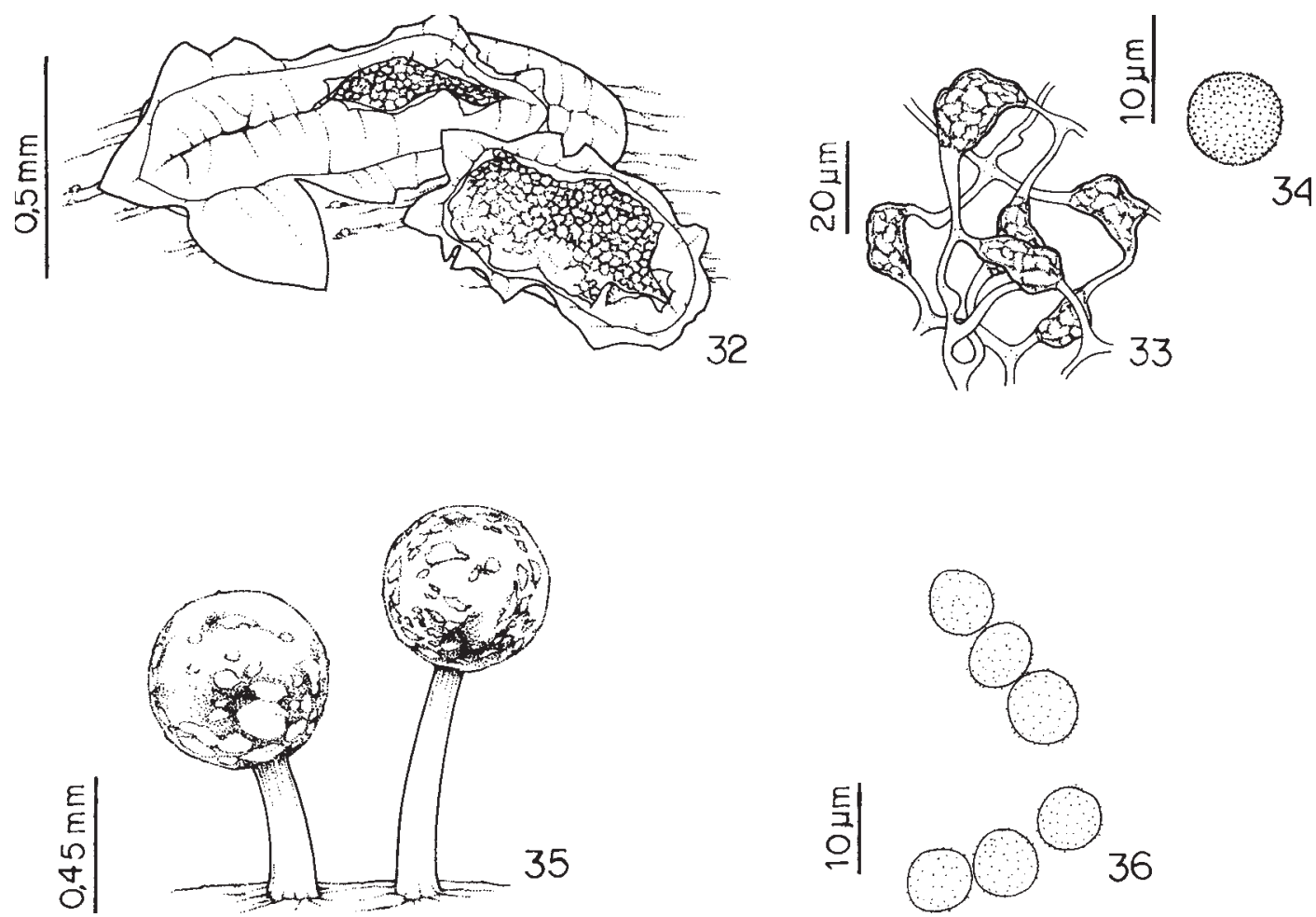

Figuras 32-34. Physarum bogoriense Racib. 32. plasmodiocarpos evidenciando o perídio duplo; 33. filamemos do capilício com nódulos de cálcio; 34. esporo. 35-36. Physarum melleum (Berk. \& Br.) Massee. 35. esporângios. 36. esporos.

cerradão, câmara-úmida, 21/IX/1999, ParentePonte 105 (UFP 27336).

Physarum pusillum (Berk. \& Curt.) G. Lister, Mycet. Ed. 2.64. 1911.

Fig. 39-40.

Esporângio pedicelado, agrupado, branco acinzentado, $1,0 \mathrm{~mm}$ alt. total; perídio simples, persistente na base, onde apresenta coloração castanho-avermelhada; hipotalo castanho enegrecido, circular, membranoso; pedicelo cilíndrico, preenchido por matéria refugada, sem cálcio, afinando levemente no ápice, castanho-avermelhado, mais escuro na base, $734,4 \mu \mathrm{m}$ compr. $\times 137,7 \mu \mathrm{m}$ larg. na base $\times 45,9 \mu \mathrm{m}$ larg. no ápice; capilício filamentoso, hialino, nódulos bastante escassos; esporo globoso, com tendência a agrupar-se e levemente anguloso, castanho-violáceo quase púrpura, minutamente verrucoso, 9,1-10,7 $\mu \mathrm{m}$ diâm.
Distribuição: cosmopolita. No Brasil, ocorre nas regiões Nordeste (BA, PE) e Sudeste (SP).

Comentários: a pigmentação castanho-avermelhada no estipe e particularmente na base esporangial permitiram identificar a amostra como Physarum pusillum e diferenciá-la de $P$. leucophaeum Fries, da qual se aproxima. Hagelstein (1944) comenta que o limite entre essas duas espécies não é bem definido. No material estudado, a parede do esporo apresenta-se minutamente verrucosa, com verrugas de tamanho uniforme, como descrito por Martin \& Alexopoulos (1969). Não foram visualizadas as verrugas mais salientes, isoladas ou agrupadas, apontadas por Farr (1976).

Material examinado: BRASIL. Piauí: Teresina, Parque Zoobotânico, cerradão, área sombreada, 18/IV/1999, Parente-Ponte 67 (UFP 27340). 

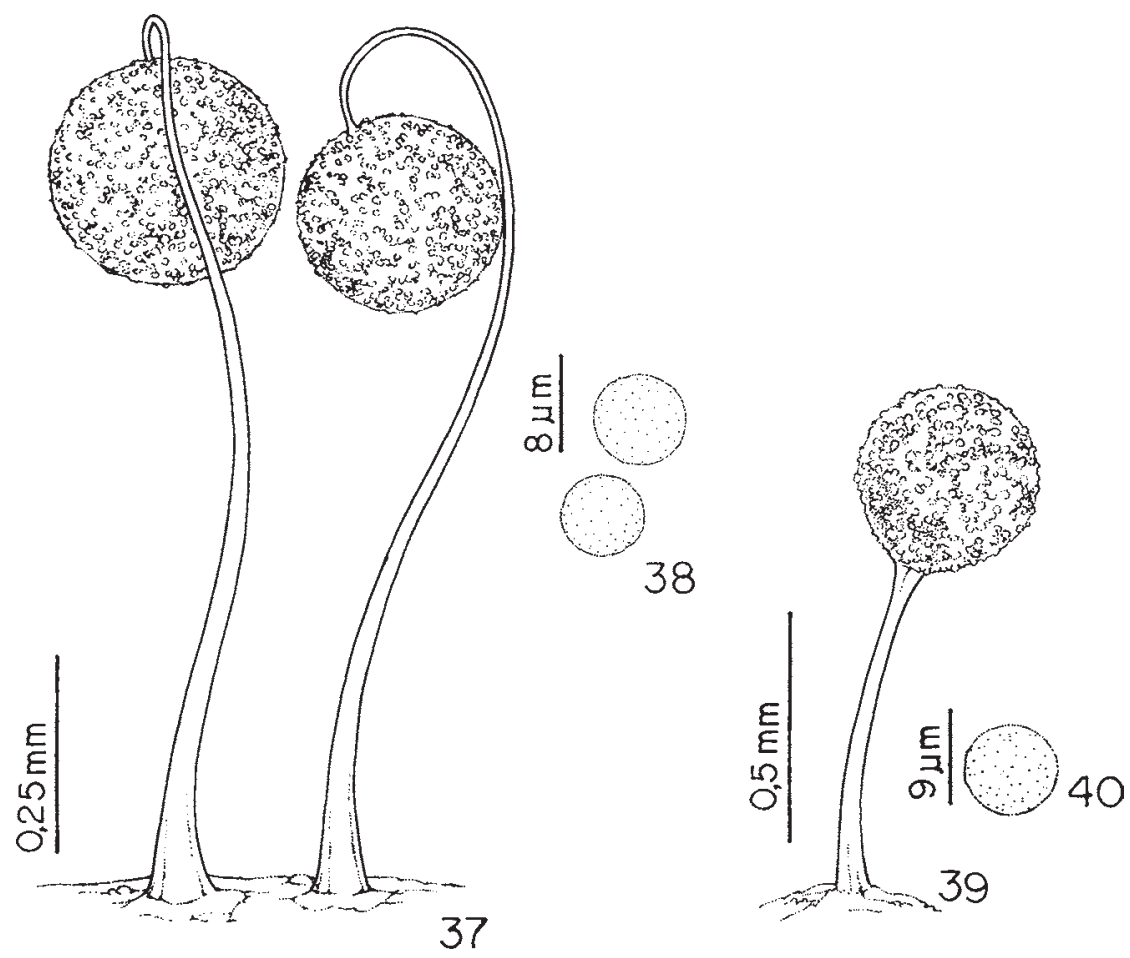

Figuras 37-38. Physarum nucleatum Rex. 37. esporângios; 38. esporos. 39-40. Physarum pusillum (Berk. \& Curt.) G. Lister. 39. esporângio; 40. esporo.

\section{Stemonitaceae}

Comatricha typhoides (Bull.) Rost. in Lister, Mycet. 120. 1894.

Fig. 41-44.

Esporângio pedicelado, cilíndrico, isolado a agrupado, castanho-acinzentado enegrecido, 3,0$5,0 \mathrm{~mm}$ alt. total; perídio parcialmente evanescente, ocasionalmente persistindo na base; hipotalo castanho-avermelhado, circular, membranoso e brilhante; pedicelo cilíndrico, castanho-avermelhado a enegrecido, $2760 \mu \mathrm{m}$ compr. $\times 122,4 \mu \mathrm{m}$ larg. na base $\times 45,9 \mu \mathrm{m}$ larg. no ápice; columela cilíndrica, afinando para o ápice, ramificando-se em toda a extensão; capilício com filamentos primários e secundários delicados, castanho-violáceos, lisos, com tendência à dicotomia, sem rede peridial, 1,5-3,0(4,5) $\mu$ m diâm.; esporo globoso, castanhovioláceo claro, levemente verrucoso, com os típicos grupos de verrugas mais salientes, 6,1-7,6 $\mu$ m diâm.

Distribuição: cosmopolita. No Brasil, ocorre nas regiões Norte (AM, RR), Nordeste (BA, CE, PB, PE, PI), Sudeste (SP) e Sul (PR, RS).

Comentários: os exemplares coletados apresentam as características típicas da espécie, principalmente pelos grupos de verrugas presentes nos esporos; em alguns espécimes podia-se notar a bainha prateada no pedicelo, como enfatizado por Lister (1925) e Farr (1976). Por não ser uma espécie muito característica do gênero, Nannenga-Bremekamp (1967) colocou-a no subgênero Stemonitopsis, não reconhecido por Martin et al. (1983). Para o Piauí, Mobin (1997) e Mobin \& Cavalcanti (1999b) assinalaram esta espécie no Parque Nacional de Sete Cidades.

Material examinado: BRASIL. Piauí: Teresina, Parque Zoobotânico, cerradão, área 
sombreada, 10/IV/1999, Parente-Ponte 30 (UFP 27372); idem, 10/IV/1999, Parente-Ponte 36 (UFP 27371); idem, 10/IV/1999, Patente Ponte 40 (UFP 27370); idem, 18/IV/1999, Parente-Ponte 70 (UFP 27366); idem, 18/IV/ 1999, Parente-Ponte 72 (UFP 27365); área iluminada, 11/IV/1999, Parente-Ponte 44 (UFP 27369); idem, 11/IV/1999, Parente-Ponte 45 (UFP 27368); idem, 11/IV/1999, Parente-Ponte 46 (UFP 27367).
Stemonitis smithii Macbr., Bull. Lab. Nat. Hist. Iowa State Univ. 2: 381. 1893.

Fig. 45- 48.

Esporângio pedicelado, cilíndrico, agrupado em tufo, castanho-acinzentado, 4,0 mm alt. total; perídio totalmente evanesceme; hipotalo contínuo, comum a vários esporocarpos, castanho-avermelhado, irregular, membranoso e brilhante; pedicelo cilíndrico, castanho-
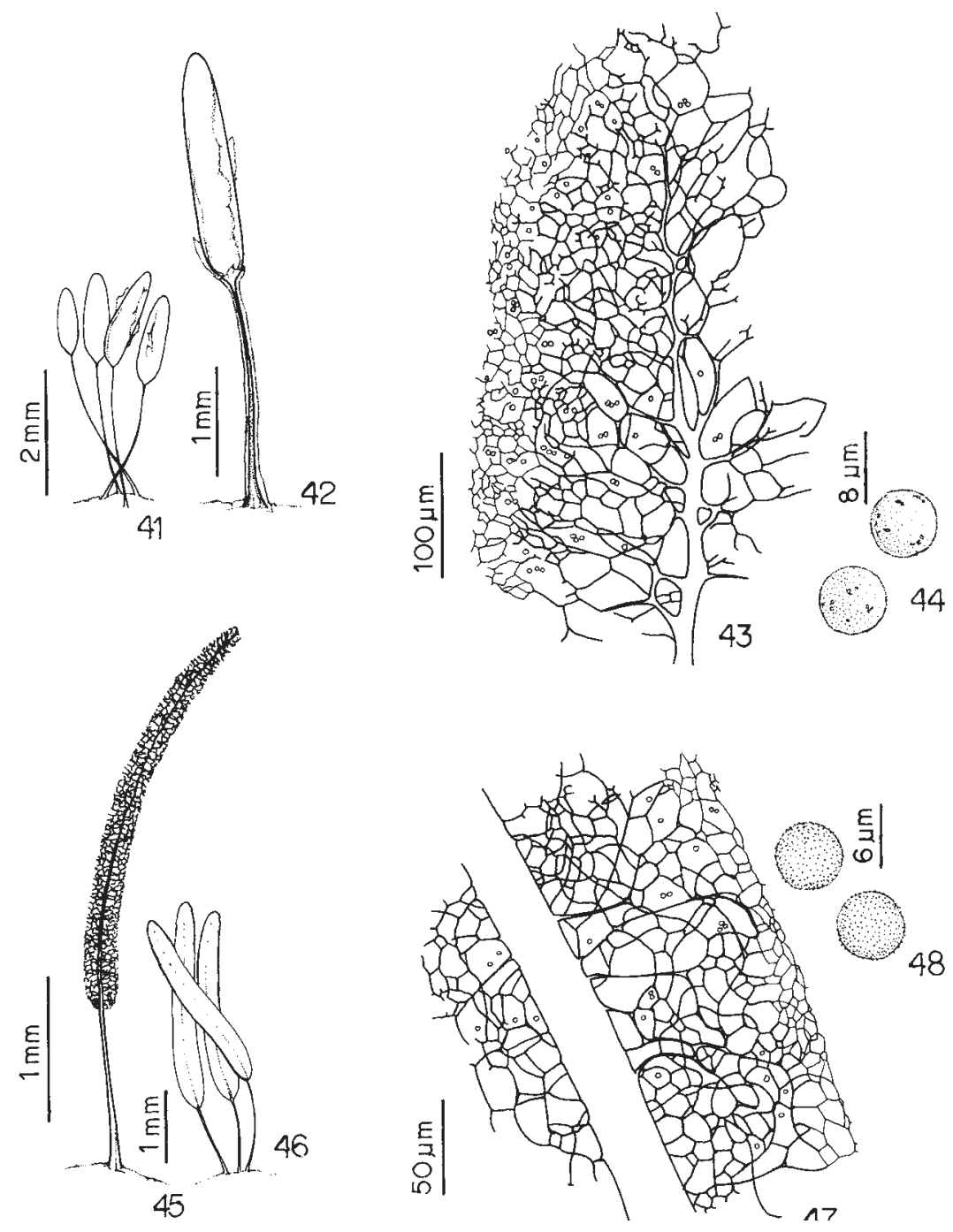

Figuras 41-44. Comatricha typhoides (Bull.) Rost. 41. grupo de esporângios; 42. esporângio evidenciando a bainha ao longo do pedicelo e vestígios do perídio; 43. detalhe do ápice da esporoteca evidenciando o capilício e columela; 44. esporos evidenciando grupos de verrugas mais saliemes. 45-48. Stentonitis smithii Macbr. 45-46. esporângios; 47. detalhe da columela e capilício. 48. esporos. 
enegrecido, $1150 \mu \mathrm{m}$ compr. $\times 91,8 \mu \mathrm{m}$ larg. na base $\times 61,2 \mu \mathrm{m}$ larg. no ápice; columela cilíndrica, ramificada, afinando para o ápice; capilício com filamemos primários e secundários delicados apresentando expansões como se fossem nódulos escuros próximos às ramificações; rede peridial periférica persistente, malhas pequenas, 11,4-6,6 um diâm.; esporo globoso, castanhovioláceo claro, livre, quase liso, 5,8-6,1 $\mu$ m diâm.

Distribuição: América Central, América do Norte temperada e tropical, América do Sul, Ásia, Europa, Nova Zelândia. No Brasil, ocorre nas regiões Norte (RR), Nordeste (PE, PI), Sudeste (MG, SP, RJ) e Sul (PR, SC).

Comentários: apenas uma amostra desta espécie foi coletada, já bastante danificada por fungos, mas as características apresentadas enquadram-se bem em Stemonitis smithii Macbr. Esta espécie é considerada como uma variedade de S. axifera (Bull.) Macbr. por vários autores, como Farr (1976) e PalmaRodriguez \& Torres-Estrada (1996), porém, no presente trabalho, foi adotada a posição de Martin \& Alexopoulos (1969), que as consideram como espécies distintas. S. smithii foi referida por Mobin (1997) e Mobin \& Cavalcanti (1999b) para o Piauí, encontrada no município de Piripiri.

Material examinado: BRASIL. Piauí: Teresina, Parque Zoobotânico, cerradão, área sombreada, 18/IV/1999, Parente-Ponte 63 (UFP 27342).

\section{Agradecimentos}

As autoras agradecem à direção do Parque Zoobotânico de Teresina pelas facilidades concedidas durante o período de coleta; à CAPES e ao CNPq, pela concessão de bolsas; aos Departamemos de Biologia da Universidade Estadual do Piauí e da Universidade Federal Rural de Pernambuco, assim como ao Departamemo de Botânica da Universidade Federal de Pernambuco, onde o estudo foi realizado, pela cooperação.

\section{Referências bibliográficas}

Alves, M. H. \& Cavalcanti, L. H. 1996. Myxomycetes em palmeiras (Arecaceae). Acta Botanica Brasilica 10(1): 1-7.

Cavalcanti, L. H. 1974. Mixomicetos corticícolas do cerrado de Emas (Pirassununga - São Paulo). Dissertação de Mestrado. Universidade de São Paulo, São Paulo.

Cavalcanti, L. H. \& Fortes, S. T. 1994. Myxomycetes de Florianópolis (Santa Catarina-Brasil). Acta Botanica Brasilica 8(10): 65-75.

Cavalcanti, L. H. \& Fortes, S. T. 1995. Myxomycetes do Estado de Santa Catarina (Brasil). Boletim da Sociedade Broteriana 67: 23-35.

Cavalcanti, L. H. \& Mobin, M. 2001. Hemitrichia serpula var. piauiensis (Trichiaceae, Myxomycetes) - A new variety from Brazil. Acta Botanica Brasilica 15(1): 133-137.

Cavalcanti, L. H.; Okada, K. \& Costa, S. P. S. E. 1993. Incidência de Myxomycetes na necromassa da Mata do Curado (Recife - PE, Brasil). Revista Nordestina de Biologia 8(1): 34-44.

Cavalcanti, L. H. \& Putzke, J. 1998. Myxomycetes da Chapada do Araripe (Crato-CE, Brasil). Acta Botanica Brasilica 12(3): 253-261.

Cavalcanti, L. H.; Santos, E. J. \& Gomes, N. A. 1999. Myxomycetes do Estado de Roraima, com especial atenção para a Estação Ecológica de Maracá (Amajari-RR, Brasil). Acta Amazonica 29(2): 195-200.

Farr, M. L. 1960. The Myxomycetes of the IMUR Herbarium with special reference to Brazilian species. Publicações do Instituto de Micologia 184: $1-54$.

Goés Neto, A. 1996. Biodiversidade de mixomicetos e fungos macroscópicos da Reserva Biológica de Una e áreas adjacentes (Bahia, Brasil). Sitientibus 15: 91-108.

Hagelstein, R. 1944. The Mycetozoa of North America. Published by the author, Mineola.

Hochgesand, E. \& Gottsberger, G. 1996. Myxomycetes from the State of São Paulo, Brazil. Boletim do Instituto de Botânica 10: 1-46.

Keller, H. W. \& Eliasson, U. H. 1992. Taxonomic evaluation of Perichaena depressa and Perichaena quadrata based on controlled cultivation, with additional observations on the genus. Mycological Research 96(12): 1085-1097. 
Lado, C. \& Pando, F. 1997. Myxomycetes, I. Ceratiomyxales, Echinosteliales, Liceales, Trichiales. Flora Micologica Iberica. Volume 2. Consejo Superior de Investigaciones Científicas, Madrid.

Lister, A. 1925. A monograph of the Mycetozoa. British Museum Natural History, London.

Martin, G. W. \& Alexopoulos, C. J. 1969. The Myxomycetes. University of Iowa Press, Iowa.

Martin, G. W.; Alexopoulos, C. J. \& Farr, M. L. 1983. The Genera of Myxomycetes. University of Iowa Press, Iowa.

Mobin, M. 1997. Myxomycetes e fungos micófilos ocorrentes em palmeiras no Parque Nacional de Sete Cidades ( Piripiri - Piauí - Brasil ). Dissertação de Mestrado. Universidade Federal de Pernambuco, Recife.

Mobin, M. \& Cavalcanti, L. H. 1998/1999. Myxomycetes sobre buriti (Mauritia flexuosa L. f., Arecaceae). Revista da Universidade do Amazonas, Série Ciências Biológicas 2/23 (1-2): 43-51.

Mobin, M. \& Cavalcanti, L. H. 1999a. Physarales (Myxomycetes) do Parque Nacional de Sete Cidades, Piauí, Brasil. Hoehnea 26(1): 1-14.

Mobin, M. \& Cavalcanti, L. H. 1999b. Stemonitales (Myxomycetes) do Parque Nacional de Sete Cidades (Piauí, Brasil). Acta Botanica Brasilica 13(2): 139-148.

Mobin, M. \& Cavalcanti, L. H. 2000. Myxomycetes em carnaubeira (Copernicia prunifera (Miller) $\mathrm{H}$. E. Moore, Arecaceae). Acta Botanica Brasilica 14(1): 71-75.
Nannenga-Bremekamp, N. E. 1967. Notes on the Myxomycetes XII. A revision of the Stemonitales. Proceedings of the Koninklije Nederlandse Akademie van Wetenschappen 70(20): 201-216.

Palma-Rodriguez, M. \& Torres-Estrada, A. 1996. Some Stemonitales (Myxomycetes) from the State of Tlaxcala, México. Mycotaxon 60: 79-102.

Ponte, M. P. M. P., Cavalcanti, L. H. \& Mobin, M. 1999. Espécies de Hemitrichia (Myxomycetes) ocorrentes em babaçu (Attalea speciosa Mart. ex Spreng., Arecaceae) no Parque Estadual Zoobotânico na Cidade de Teresina, Piauí - Brasil. Pp. 98-102. In: Anais do I Simpósio de Produção Científica da UESPI. Teresina

Pôrto, K. C. 1982. Myxomycetes da Mata de Dois Imãos (Recife-Pernambuco). Dissertação de Mestrado. Universidade Federal Rural de Pernambuco, Recife.

Pôrto, K. C.; Cavalcanti, L. H. \& Correia, A. M. S. 1985. Incidência de Myxomycetes em Palmae. Pp.181-187. In: Anais do XXXIII Congresso Nacional de Botânica. EMBRAPA, Brasília.

Putzke, J. 1996. Myxomycetes do Brasil. Caderno de Pesquisa, Série Botânica 8(1/2): 1- 85 .

Rizzuto, M.C.C. 1997. Sistemática e ecologia das Stemonitales ocorrentes nas Matas do Sistema Gurjaú (Cabo-PE). Dissertação de Mestrado. Universidade Federal de Pernambuco, Recife.

Teixeira, A. R. 1971. Gêneros de Myxomycetes. Rickia supl. 4: 1-150.

Torrend, C. 1915. Les Myxomycètes du Brésil, connus jusqu'ici. Broteria, Série Botânica 13: 72-88. 